\title{
Clinical Features of COVID-19 Hospitalized Patients with and without Chronic Kidney Disease: A Single-Center, Cross-Sectional Study
}

\author{
Morteza Ahmadzadeh-Darinsoo ${ }^{1}$ (i), Mostafa Akbariqomi ${ }^{1}$ (i), Mojtaba Ahmadzadeh-Darinsoo ${ }^{1}(\mathbb{C})$,

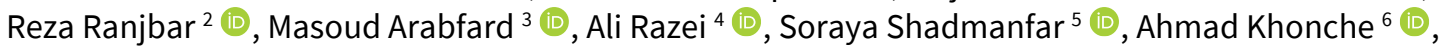

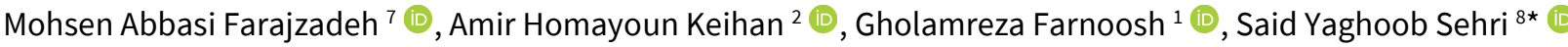

${ }^{1}$ Applied Biotechnology Research Centre, Baqiyatallah University of Medical Sciences, Tehran, IRAN

${ }^{2}$ Molecular Biology Research Center, Systems Biology and Poisonings Institute, Baqiyatallah University of Medical Sciences, Tehran, IRAN

${ }^{3}$ Chemical Injuries Research Center, Systems Biology and Poisonings Institute, Baqiyatallah University of Medical Sciences, Tehran, IRAN

${ }^{4}$ Applied Microbiology Research Center, Systems Biology and Poisonings Institute, Baqiyatallah University of Medical Sciences, Tehran, IRAN

${ }^{5}$ Rheumatology Department, Baqiyatallah Hospital, Baqiyatallah University of Medical Sciences, Tehran, IRAN

${ }^{6}$ Department of Internal Medicine, Baqiyatallah University of Medical Sciences, Tehran, IRAN

${ }^{7}$ Health Management Research Center, Baqiyatallah University of Medical Sciences, Tehran, IRAN

${ }^{8}$ Nephrology and Urology Research Center, Baqiyatallah University of Medical Sciences, Tehran, IRAN

*Corresponding Author: Saidyaghoobsehri@yahoo.com

Citation: Ahmadzadeh-Darinsoo M, Akbariqomi M, Ahmadzadeh-Darinsoo M, Ranjbar R, Arabfard M, Razei A, Shadmanfar S, Khonche A, Abbasi Farajzadeh M, Keihan AH, Farnoosh G, Sehri SY. Clinical Features of COVID-19 Hospitalized Patients with and without Chronic Kidney Disease: A Single-Center, Cross-Sectional Study. Electron J Gen Med. 2022;19(2):em345. https://doi.org/10.29333/ejgm/11544

\section{ARTICLE INFO}

Received: 11 Sep. 2021

Accepted: 7 Jan. 2022

\section{ABSTRACT}

Background and Objectives: The severity and mortality of coronavirus disease 19 (COVID-19) caused by severe acute respiratory syndrome coronavirus-2 are positively associated with underlying diseases such as hypertension, diabetes, and chronic kidney disease (CKD). In this regard, the current study aimed to evaluate the clinical characteristics, laboratory findings, and outcomes of coronavirus disease 2019 (COVID-19) hospitalized patients with and without CKD.

Methods: This cross-sectional matched study was conducted on hospitalized confirmed COVID-19 patients with and without CKD admitted to Baqiyatallah Hospital in Tehran, Iran, from February 26, 2020 to March 26, 2020. The patients were homogenized in terms of age, gender, body mass index, and underlying diseases such as hypertension and diabetes. Demographic data, clinical symptoms, and laboratory and radiological findings were collected from patients' medical records and compared between the patients based on their CKD status.

Results: Among the COVID-19 patients, 56 and 97 cases with and without CKD were investigated, respectively. In general, $111(72.5 \%)$ patients with a mean age of 55 years were males. Patients with CKD had higher levels of blood urea nitrogen, creatinine, and red cell distribution width $(p<0.05)$. No differences were found regarding chest computed tomography findings, ICU admission, and death among COVID-19 patients with and without CKD.

Conclusions: Overall, the findings support the use of red cell distribution width, blood urea nitrogen, and creatinine for monitoring the COVID-19 patients with CKD and assessing the risk of disease progression. Eventually, managing comorbidities including hypertension and diabetes will reduce COVID-19 severity in CKD patients.

Keywords: chronic kidney disease, clinical characteristics, COVID-19, hospitalized

\section{INTRODUCTION}

A wide variety of individuals worldwide have been affected by the coronavirus disease 19 (COVID-19) pandemic, which is due to severe acute respiratory syndrome coronavirus-2 (SARSCoV-2). The virus has led to $140,332,386$ proved cases and over three million deaths by April 18, 2021 and the number is still increasing [1]. So far, there has been no approved antiviral agent against this infectious disease, and treatment methods are merely supportive and symptomatic [2-4]. COVID-19 can cause a range of diseases from mild to severe respiratory tract infections and multiple organ dysfunctions and may be asymptomatically transmitted between people in some cases
[2,5]. According to numerous reports, the severity and mortality of this pandemic are positively related to underlying diseases. Hypertension, chronic kidney disease (CKD), and diabetes are the most prevalent underlying diseases in patients with COVID-19, and severe cases are more likely to occur among these individuals [6-8].

In this regard, high angiotensin-converting enzyme 2 expression was reported to be a cell entry route for the SARSCoV-2 in the kidney [9]. Furthermore, SARS-CoV-2 was found in urine and kidney tissues in some COVID-19 patients, indicating that the kidney is a potential target for the virus. In a study on 701 COVID-19 patients, blood urea nitrogen (BUN) and serum creatinine increased in $13.1 \%$ and $14.4 \%$ of patients, respectively. Further, $33.7 \%$ of patients with increased baseline 
Table 1. Baseline demographics and clinical features of COVID-19 hospitalized patients with and without CKD

\begin{tabular}{|c|c|c|c|}
\hline \multirow{2}{*}{ Characteristics } & \multicolumn{2}{|c|}{ Patients, No. (\%) } & \multirow{2}{*}{ p-value } \\
\hline & With CKD (n=56) & Without CKD (n=97) & \\
\hline Age, y & & & 0.26 \\
\hline Mean \pm SD & $56.79 \pm 11.93$ & $54.35 \pm 13.20$ & \\
\hline Min-Max & $35-84$ & $22-88$ & \\
\hline Gender & & & 0.54 \\
\hline Male & $39(69.6)$ & $72(74.2)$ & \\
\hline Female & $17(30.4)$ & $25(25.8)$ & \\
\hline $\mathrm{BMI}, \mathbf{k g} / \mathrm{m}^{2}$ & & & 0.56 \\
\hline Mean \pm SD & $29.15 \pm 6.96$ & $28.53 \pm 5.12$ & \\
\hline Min-Max & $20.96-66.60$ & $17.93-44.59$ & \\
\hline \multicolumn{4}{|l|}{ Comorbidities } \\
\hline Hypertension & $23(41.1)$ & $31(32.0)$ & 0.26 \\
\hline Diabetes & $24(42.9)$ & $33(34.0)$ & 0.28 \\
\hline Heart disease & $14(25.0)$ & $18(18.6)$ & 0.32 \\
\hline Lung disease & $8(14.3)$ & $7(7.2)$ & 0.16 \\
\hline Liver disease & $12(21.4)$ & $11(11.3)$ & 0.08 \\
\hline \multicolumn{4}{|l|}{ Symptoms at admission } \\
\hline Fever (temperature $\geq 37.3^{\circ} \mathrm{C}$ ) & $33(58.9)$ & $59(60.8)$ & 0.82 \\
\hline Cough & $38(69.9)$ & $63(64.9)$ & 0.71 \\
\hline Dyspnea & $39(69.6)$ & $59(60.8)$ & 0.27 \\
\hline Chest Pain & $12(21.4)$ & $26(26.8)$ & 0.46 \\
\hline Weakness & $29(51.8)$ & $57(58.8)$ & 0.40 \\
\hline Myalgia & $27(48.2)$ & $62(63.9)$ & 0.06 \\
\hline Chill & $30(53.6)$ & $55(56.7)$ & 0.71 \\
\hline Rhinorrhea & $9(16.1)$ & $10(10.3)$ & 0.30 \\
\hline Sore Throat & $6(10.7)$ & $17(17.5)$ & 0.26 \\
\hline Diarrhea & $10(17.9)$ & $22(22.7)$ & 0.48 \\
\hline Vomiting & $18(32.1)$ & $41(42.3)$ & 0.21 \\
\hline Sputum production & $20(35.7)$ & $26(26.8)$ & 0.25 \\
\hline
\end{tabular}

Note. Min-max: Minimum-maximum; SD: Standard deviation; COVID-19: Coronavirus disease 2019; CKD: Chronic kidney disease; BMI: Body mass index. ${ }^{*} \mathrm{p}<0.05$ is statistically significant

serum creatinine died [10], highlighting the importance of COVID-19 in patients suffering from preexisting renal disorders. But, there are limited data regarding the clinical characteristics of CKD patients, who are infected with COVID-19, for better controlling the disease. Therefore, the current work aimed at evaluating and comparing the laboratory results, clinical characteristics, and consequences of COVID-19 patients with and without CKD hospitalized in different medical centers.

\section{METHODS}

\section{Participants and Study Design}

This cross-sectional study included 153 consecutive adult patients with proved COVID-19 admitted to Baqiyatallah Hospital, which is a selected hospital for the treatment of COVID-19 patients by the government, from 12 March to 10 April 2020. Among the patients, 56 COVID-19 adults with CKD and 97 controls without CKD were homogenized with regard to age, body mass index, gender, and underlying diseases such as diabetes and hypertension. COVID-19 was detected based on the interim guidance, which was issued by the World Health Organization. All COVID-19 patients were confirmed by the reverse transcription-polymerase chain reaction for SARS-CoV2 RNA with nasopharyngeal specimens, and the follow-up was performed for the clinical outcomes until 18 April 2020. The present work was conducted under the approval of the Ethics Committee of the Baqiyatallah University of Medical Sciences, Iran (IR.BMSU.REC.1399.171). Based on the retrospective design of this study, written informed consent forms were obtained from all patients.

\section{Data Collection and Statistical Analysis}

The demographic data, chest computed tomography (CT) scans, laboratory findings, clinical symptoms, and outcomerelated data of all patients were obtained from electronic medical records. The patients with missing data on the studied criteria and kidney transplant recipients were excluded from the study. Patients with CKD were identified based on the selfdeclaration form or medical documents confirmed by a nephrologist. Based on the Kidney Disease: Improving Global Outcomes, CKD was defined as the glomerular filtration rate $\left(<60 \mathrm{~mL} / \mathrm{min} / 1.73 \mathrm{~m}^{2}\right)$ for a minimum of three months [11]. Eventually, patients' clinical outcomes were evaluated by experienced clinicians.

Categorical and continuous variables were expressed as the percentage (\%) and mean \pm standard deviation (SD), respectively. In addition, categorical and continuous variables were analyzed by the chi-square test/Fisher's exact test and independent t-test/Mann-Whitney $U$ test, respectively. A $P$ value less than 0.05 represented a statistically significant difference. Finally, SPSS software (version 22.0, IBM) was used to analyze the obtained data.

\section{RESULTS}

In general, 153 patients (56 and 97 patients with and without CKD, respectively) suffering from confirmed COVID-19 were included in this cross-sectional study. Table 1 represents the demographic and clinical characteristics of COVID-19 hospitalized patients with and without CKD. Based on the 
Table 2. The radiographic and laboratory results among COVID-19 hospitalized patients with and without CKD

\begin{tabular}{|c|c|c|c|}
\hline \multirow{2}{*}{ Characteristics (normal range) } & \multicolumn{2}{|c|}{ Patients, Mean \pm SD } & \multirow{2}{*}{ p-value* } \\
\hline & With CKD (n=56) & Without CKD ( $n=97)$ & \\
\hline \multicolumn{4}{|l|}{ Laboratory findings at admission } \\
\hline $\begin{array}{c}\text { Leucocyte count, } \times 10^{9} / \mathrm{L}(3.5-9.5) \\
\end{array}$ & $8.09 \pm 8.49$ & $6.42 \pm 2.53$ & 0.185 \\
\hline Neutrophil count, \% (50-70) & $69.13 \pm 14.28$ & $71.23 \pm 12.43$ & 0.406 \\
\hline Lymphocyte count, \% (11-49) & $22.80 \pm 11.48$ & $22.71 \pm 11.16$ & 0.966 \\
\hline RBC count, $\times 10^{12} / \mathrm{L}(4.3-5.8)$ & $4.83 \pm 0.82$ & $4.95 \pm 0.53$ & 0.383 \\
\hline Hemoglobin, g/dL (13.3-16.9) & $13.55 \pm 2.15$ & $14.61 \pm 1.48$ & 0.003 \\
\hline Hematocrit, \% (39-51) & $40.17 \pm 5.37$ & $42.38 \pm 3.72$ & 0.014 \\
\hline MCV, fL (80-98) & $84.01 \pm 7.90$ & $86.11 \pm 5.10$ & 0.102 \\
\hline $\mathrm{MCH}, \mathrm{pg}(27-35)$ & $28.35 \pm 3.67$ & $29.68 \pm 2.26$ & 0.026 \\
\hline MCHC, g/dL (31-36) & $33.64 \pm 1.87$ & $34.45 \pm 1.19$ & 0.008 \\
\hline Platelet count, $\times 10^{9} / \mathrm{L}(125-350)$ & $201.75 \pm 79.56$ & $182.47 \pm 64.14$ & 0.136 \\
\hline RDW-CV, \% (11.5-15.5) & $13.68 \pm 1.67$ & $13.06 \pm 0.99$ & 0.013 \\
\hline MPV, fL (6-13.5) & $10.14 \pm 1.17$ & $10.15 \pm 0.97$ & 0.951 \\
\hline $\mathrm{ESR}, \mathrm{mm} / \mathrm{h}(0-20)$ & $43.68 \pm 24.61$ & $41.43 \pm 25.69$ & 0.638 \\
\hline $\mathrm{CRP}, \mathrm{mg} / \mathrm{L}(0-10)$ & $44.34 \pm 22.58$ & $45.69 \pm 28.04$ & 0.760 \\
\hline $\mathrm{BS}, \mathrm{mg} / \mathrm{dL}(70-126)$ & $153.50 \pm 84.34$ & $149.07 \pm 83.44$ & 0.816 \\
\hline BUN, mg/dL (7-19) & $19.38 \pm 7.63$ & $13.16 \pm 4.57$ & $<0.001$ \\
\hline Creatinine, $\mathrm{mg} / \mathrm{dL}(0.9-1.3)$ & $1.58 \pm 0.18$ & $1.06 \pm 0.28$ & $<0.001$ \\
\hline AST, U/L (<35) & $39.76 \pm 25.24$ & $34.75 \pm 15.04$ & 0.316 \\
\hline $\mathrm{ALT}, \mathrm{U} / \mathrm{L}(<45)$ & $40.94 \pm 40.52$ & $32.33 \pm 16.97$ & 0.247 \\
\hline ALP, U/L (up to 270 ) & $217.84 \pm 179.30$ & $182.50 \pm 78.61$ & 0.299 \\
\hline LDH, U/L (207-414) & $666.90 \pm 207.27$ & $654.32 \pm 271.45$ & 0.836 \\
\hline Sodium, mEq/L (136-145) & $136.64 \pm 4.24$ & $131.10 \pm 21.80$ & 0.089 \\
\hline Potassium, mEq/L (3.5-5) & $4.22 \pm 0.49$ & $5.98 \pm 15.77$ & 0.447 \\
\hline \multicolumn{4}{|l|}{ Chest CT findings, No.\% } \\
\hline Bilateral lung involvement & $55(98.2)$ & $92(94.8)$ & 0.301 \\
\hline Ground-glass opacity & $51(91.1)$ & $91(93.8)$ & 0.527 \\
\hline Consolidation shadow & $5(8.9)$ & $5(5.2)$ & 0.363 \\
\hline
\end{tabular}

Note. COVID-19: Coronavirus disease 2019; MCV: Mean corpuscular volume; CKD: Chronic kidney disease; RBC: Red blood cell; MCH: Mean corpuscular hemoglobin; RDW: Red cell distribution width, RDW-CV; MCHC: Mean corpuscular hemoglobin concentration; MPV: Mean platelet volume; ESR: Erythrocyte sedimentation rate; CRP: C-reactive protein; BS: Blood sugar; BUN: Blood urea nitrogen, BUN; AST: Aspartate aminotransferase; ALT: Alanine aminotransferase; ALP: Alkaline phosphatase; LDH: Lactate dehydrogenase; No.: Number; SD: Standard deviations; CT: Computed tomography. ${ }^{*} \mathrm{p}<0.05$ is considered statistically significant. The values in bold represent a significant difference

results, no differences were found between the two groups in terms of age, gender, and underlying comorbidities (i.e., hypertension and diabetes) due to the matching design $(p \geq 0.05)$. The mean ( $\pm S D)$ age of patients with and without CKD was $56.79( \pm 11.93)$ and $54.35( \pm 13.20)$ years, respectively, and most patients $(72.5 \%)$ were males. Furthermore, no considerable differences were observed regarding clinical symptoms between the groups at the time of admission $(p \geq 0.05)$.

Table 2 summarizes the comparison results of laboratory and radiographic findings between patients with and without CKD. The erythrocyte sedimentation rate (ESR, 43.68 \pm 24.61 $\mathrm{mm} / \mathrm{h}$ ), C-reactive protein (CRP, $44.34 \pm 22.58 \mathrm{mg} / \mathrm{L}$ ), blood sugar (BS, $153.5 \pm 84.34 \mathrm{mg} / \mathrm{dL})$, BUN $(19.38 \pm 7.63 \mathrm{mg} / \mathrm{dL})$, creatinine $(1.58 \pm 0.18 \mathrm{mg} / \mathrm{dL})$, aspartate aminotransferase (AST, 39.76 $\pm 25.24 \mathrm{U} / \mathrm{L}$ ), and lactate dehydrogenase (LDH, $666.9 \pm 207.27 \mathrm{U} / \mathrm{L}$ ) were above the normal range in CKD patients. Based on laboratory findings, COVID-19 patients with CKD were at higher risk of inflammatory responses and myocardial and hepatic damages, leading to the unfavorable prognosis of COVID-19.

Regarding laboratory results on admission, CKD patients also demonstrated higher levels of BUN (19.38 \pm 7.63 vs. $13.16 \pm 4.57 \mathrm{mg} / \mathrm{dL}, \mathrm{p}<0.001)$, creatinine $(1.58 \pm 0.18 \mathrm{vs} .1 .06 \pm 0.28$ $\mathrm{mg} / \mathrm{dL}, \mathrm{p}<0.001$ ), and red cell distribution width (RDW-CV, $13.68 \pm 1.67$ vs. $13.06 \pm 0.99, p=0.013$ ) compared to patients without CKD. Nonetheless, the values of hematological parameters (Table 2) were lower, including hemoglobin
(13.55 \pm 2.15 vs. $14.61 \pm 1.48 \mathrm{~g} / \mathrm{dL}, \mathrm{p}=0.003)$, hematocrit $(40.17 \pm 5.37 \%$ vs. $42.38 \pm 3.72 \%, p=0.014)$, mean corpuscular hemoglobin ( $\mathrm{MCH}, 28.35 \pm 3.67$ vs. $29.68 \pm 2.26 \mathrm{pg}, \mathrm{p}=0.026$ ), and mean corpuscular hemoglobin concentration (MCHC, $33.64 \pm 1.87$ vs. $34.45 \pm 1.19 \mathrm{~g} / \mathrm{dL}, \mathrm{p}=0.008$ ).

On admission, chest CT abnormalities were detected in most patients. There was no significant difference between the CT or chest radiography results of COVID-19 patients with and without CKD (Table 3). Based on the results, bilateral lung involvement and ground-glass opacities were the most prevalent CT abnormalities. According to data in Table 3, no significant difference was found in mortality rates, ICU admission, and length of hospital stay between patients with and without CKD.

\section{DISCUSSION}

COVID-19 is a highly contagious and newly evolved disease related to the enhanced rates of hospitalization and mortality, especially in individuals with underlying diseases. Limited data exist on the clinical characteristics of COVID-19 hospitalized patients with CKD. The present paper sought to discuss and compare the clinical characteristics and differences between COVID-19 patients with and without CKD.

Based on the results, the proportions of male patients in the present work $(72.5 \%)$ were higher compared to females, which is in line with the findings of previous studies $[12,13]$. 
Table 3. Clinical outcomes of COVID-19 hospitalized patients with and without CKD

\begin{tabular}{lccc}
\hline \multirow{2}{*}{ Characteristics } & \multicolumn{2}{c}{ Patients, No. (\%) } & \multirow{2}{*}{ p-value $^{*}$} \\
\cline { 2 - 3 } & \multicolumn{1}{c}{ With CKD (n=56) } & Without CKD ( $\mathbf{n = 9 7 )}$ & 0.194 \\
\hline Length of hospital stay, Mean $\pm S D$, days & $6.25 \pm 4.3$ & $5.35 \pm 3.7$ & 0.540 \\
\hline Hospital discharge & $33(58.9)$ & $62(63.9)$ & 0.830 \\
\hline ICU admission & $7(12.5)$ & $11(11.3)$ & 0.200 \\
\hline Death & $5(8.9)$ & $6(6.2)$ &
\end{tabular}

Note. COVID-19: Coronavirus disease 2019; CKD: Chronic kidney disease; ICU: Intensive care unit; No.: Number; SD: Standard deviations. " $\mathrm{p}<0.05$ shows the statistical significance

They also suffered from more severe symptoms that were related to old age, nicotine dependence, and a higher number of comorbidities.

According to recent studies, CKD is among the most widespread comorbidities in COVID-19 patients [14]. In the current study, hypertension and diabetes between patients with and without CKD were matched for assessing the direct impact of CKD on the severity and death of COVID-19. No considerable differences were found in the clinical manifestation, radiological findings, and mortality rates between patients with and without CKD. These data revealed that the increased severity and mortality rate of the disease in COVID-19 patients with CKD, which was reported in other studies [15-17], may not be directly related to CKD per se. This means that other comorbidities, especially hypertension and diabetes, have great impacts on the undesirable outcomes of COVID-19 patients with CKD.

Laboratory findings in all admitted patients indicated higher CRP, LDH, and ESR rates than the normal range, revealing a severe status and multi-organ damage, which is consistent with the findings of earlier studies [18, 19]. Moreover, kidney damage indexes (i.e., the level of BUN and creatinine) were higher than the normal range and were also considerably higher in patients with CKD in comparison with patients without CKD. Conversely, the RDW-CV value significantly increased in patients with CKD compared to ones without CKD. This was reported as an important predictor for the severity of COVID-19 patients in previous studies [20-22]. However, other observed RBC indexes were significantly lower in CKD patients.

In the present study, although chest radiographic findings showed pulmonary involvement in all patients, there was no significant difference regarding the type of pulmonary manifestations between COVID-19 patients with and without CKD.

Additionally, no considerable differences were detected in the length of hospital stay, ICU admission, rate of hospital discharge, and mortality between the two groups during the follow-up. These results could highlight the importance of other comorbidities on the severity of COVID-19 infections in our study population.

This study has some limitations. The related data were only obtained from patients from a single center in Tehran. Accordingly, it would be more valuable to achieve more complete results by conducting larger studies in a multicenter manner. In addition, the data were acquired via electronic medical records, thus this study might not be unbiased regarding the missing data.

\section{CONCLUSIONS}

In general, RDW-CV, BUN, and creatinine were essential laboratory indexes for monitoring COVID-19 patients with CKD and evaluating the risk of disease progression in this study. It was found that disease severity and in-hospital mortality in COVID-19 patients with CKD are possibly correlated with other comorbidities, especially hypertension and diabetes rather than the ones caused by CKD per se. Therefore, the optimal management of these risk factors would be effective in preventing the development of critical circumstances and performing effective treatment measures.

Author contributions: All authors have sufficiently contributed to the study, and agreed with the results and conclusions.

Funding: No funding source is reported for this study.

Acknowledgements: All authors would like to acknowledge the Clinical Research Development Unit of Baqiyatallah Hospital for advice and guidance.

Declaration of interest: No conflict of interest is declared by authors.

\section{REFERENCES}

1. World Health Organization (WHO). Coronavirus disease 2019 (COVID-19): Weekly epidemiological update on COVID-19-20 April 2021. Available at: https://www.who.int/ publications/m/item/weekly-epidemiological-update-oncovid-19---20-april-2021 (Accessed: 20 April 2021)

2. Arons MM, Hatfield KM, Reddy SC, et al. Presymptomatic SARS-CoV-2 infections and transmission in a skilled nursing facility. N Engl J Med 2020;382(22):2081-90. https://doi.org/10.1056/NEJMoa2008457 PMid:32329971 PMCid:PMC7200056

3. Corbellini C, Villafane J, Gugliotta E, et al. Late breaking abstract-Pulmonary rehabilitation in post-COVID subjects with moderate lung restriction, a case series. Eur Respir J 2021;58:PA2003. https://doi.org/10.1183/13993003. congress-2021.PA2003

4. Reviriego GB, Pascual BP, Ruiz AR, et al. Spanish experience of pulmonary rehabilitation efficacy for patients affected by the novel SARS-CoV-2 (COVID-19): A case report. Top Geriatr Rehabil 2020;36(4):212-4. https://doi.org/ 10.1097/TGR.0000000000000283

5. Farnoosh G, Akbariqomi M, Badri T, Bagheri M, Izadi M, Saeedi-Boroujeni A, et al. Efficacy of a low dose of melatonin as an adjunctive therapy in hospitalized patients with COVID-19: A randomized, double-blind clinical trial. Arch Med Res. 2021 Jun 23. https://doi.org/10.1016/ j.arcmed.2021.06.006 PMid:34229896 PMCid:PMC8220995 
6. Emami A, Javanmardi F, Pirbonyeh N, Akbari A. Prevalence of underlying diseases in hospitalized patients with COVID19: A systematic review and meta-analysis. Arch Acad Emerg Med 2020;8(1):e35. https://doi.org/10.1371/journal. pone.0241265 PMid:33095835 PMCid:PMC7584167

7. Flythe JE, Assimon MM, Tugman MJ, et al. Characteristics and outcomes of individuals with pre-existing kidney disease and COVID-19 admitted to intensive care units in the United States. Am J Kidney Dis 2021;77(2):190-203.e1. https://doi.org/10.1053/j.ajkd.2020.09.003 PMid:32961244 PMCid:PMC7501875

8. Akbariqomi M, Hosseini MS, Rashidiani J, et al. Clinical characteristics and outcome of hospitalized COVID-19 patients with diabetes: A single-center, retrospective study in Iran. Diabetes Res Clin Pract 2020;169:108467. https://doi.org/10.1016/j.diabres.2020.108467 PMid: 32979419 PMCid:PMC7513687

9. Fan C, Lu W, Li K, Ding Y, Wang J. ACE2 Expression in kidney and testis may cause kidney and testis infection in COVID19 patients. Front Med 2021;7:563893. https://doi.org/ 10.3389/fmed.2020.563893 PMid:33521006 PMCid: PMC7838217

10. Cheng $\mathrm{Y}$, Luo R, Wang $\mathrm{K}$, et al. Kidney disease is associated with in-hospital death of patients with COVID-19. Kidney Int 2020;97(5):829-38. https://doi.org/10.1016/j.kint.2020.03. 005 PMid:32247631 PMCid:PMC7110296

11. Levin A, Stevens PE, Bilous RW, et al. KDIGO 2012 clinical practice guideline for the evaluation and management of chronic kidney disease. Kidney Int Suppl 2013;3(1):1-150. https://doi.org/10.1038/kisup.2012.73 PMCid:PMC4089625

12. Peckham H, de Gruijter NM, Raine C, et al. Male sex identified by global COVID-19 meta-analysis as a risk factor for death and ITU admission. Nat Commun 2020;11(1):6317. https://doi.org/10.1038/s41467-02019741-6 PMid:33298944 PMCid:PMC7726563

13. Jin J-M, Bai P, He W, et al. Gender differences in patients with COVID-19: Focus on severity and mortality. Front Public Health 2020;8:152. https://doi.org/10.3389/fpubh. 2020.00152 PMid:32411652 PMCid:PMC7201103

14. Council E-E, Group EW. Chronic kidney disease is a key risk factor for severe COVID-19: A call to action by the ERA-EDTA. Nephrol Dial Transplant 2020;36(1):87-94. https://doi.org/ 10.1093/ndt/gfaa314 PMid:33340043 PMCid:PMC7771976
15. Gansevoort RT, Hilbrands LB. CKD is a key risk factor for COVID-19 mortality. Nat Rev Nephrol 2020;16(12):705-6. https://doi.org/10.1038/s41581-020-00349-4 PMid: 32848205 PMCid:PMC7447963

16. Gasparini M, Khan S, Patel JM, et al. Renal impairment and its impact on clinical outcomes in patients who are critically ill with COVID-19: A multicentre observational study. Anaesthesia 2021;76:320-6. https://doi.org/10.1111/ anae.15293 PMid:33948938

17. Pranata R, Supriyadi R, Huang I, et al. The association between chronic kidney disease and new onset renal peplacement therapy on the outcome of COVID-19 patients: A meta-analysis. Clin Med Insights Circ Respir Pulm Med 2020;14:1179548420959165. https://doi.org/ 10.1177/1179548420959165 PMid:32994700 PMCid: PMC7502996

18. Mokhtari T, Hassani F, Ghaffari N, Ebrahimi B, Yarahmadi A, Hassanzadeh G. COVID-19 and multiorgan failure: A narrative review on potential mechanisms. J Mol Histol 2020;51(6):613-28. https://doi.org/10.1007/s10735-02009915-3 PMid:33011887 PMCid:PMC7533045

19. Ghahramani S, Tabrizi R, Lankarani KB, et al. Laboratory features of severe vs. non-severe COVID-19 patients in Asian populations: A systematic review and meta-analysis. Eur J Med Res 2020;25(1):30. https://doi.org/10.1186/ s40001-020-00432-3 PMid:32746929 PMCid:PMC7396942

20. Henry BM, Benoit JL, Benoit S, et al. Red blood cell distribution width (RDW) predicts COVID-19 severity: A prospective, observational study from the Cincinnati SARSCoV-2 Emergency Department Cohort. Diagnostics 2020;10(9):618. https://doi.org/10.3390/diagnostics100906 18 PMid:32825629 PMCid:PMC7554711

21. Wang $\mathrm{C}$, Zhang $\mathrm{H}$, Cao X, et al. Red cell distribution width (RDW): A prognostic indicator of severe COVID-19. Ann Transl Med 2020;8(19):1230. https://doi.org/10.21037/atm20-6090 PMid:33178762 PMCid:PMC7607068

22. Wang C, Deng R, Gou L, et al. Preliminary study to identify severe from moderate cases of COVID-19 using combined hematology parameters. Ann Transl Med 2020;8(9):593. https://doi.org/10.21037/atm-20-3391 PMid:32566620 PMCid:PMC7290538 